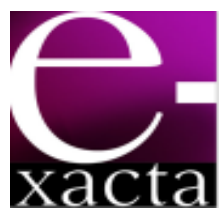

ISSN: 1984-3151

\section{EFICIÊNCIA ENERGÉTICA EM SISTEMA DE CONTROLE DE VELOCIDADE EM MOTORES DE INDUÇÃO}

\section{ENERGY EFFICIENCY IN SPEED CONTROL SYSTEM FOR INDUCTION MOTORS}

\author{
Arlete Vieira da Silva; Elisangela do Nascimento Ribeiro; \\ lana Cavalcanti Tenório; Mário Marcos Brito Horta
}

Centro Universitário de Belo Horizonte, Belo Horizonte, MG

\begin{abstract}
arlete.silva@prof.unibh.br; nr.elisangela@gmail.com; ianactenoriodgmail.com; mario bhorta@yahoo.com.br
\end{abstract}

Recebido em: 01/07/2011 - Aprovado em: 04/07/2011 - Disponibilizado em: 24/07/2011

RESUMO: Este trabalho tem o como objetivo o estudo da eficiência energética dos motores de indução alimentados por inversores de freqüência, pois este recurso é uma prática que progressivamente permitiu a substituição dos redutores mecânicos de velocidade. Neste estudo foi aprofundado o controle de velocidade dos motores de indução do tipo gaiola de esquilo através dos inversores de freqüência utilizando o controle escalar. Os motores de indução são muito utilizados em aplicações industriais devido a sua construção simples, sua baixa manutenção e seu tamanho reduzido. Foi possível, através de ensaios realizados no laboratório de Engenharia Elétrica do UniBH, obter resultados satisfatório em relação ao desempenho do funcionamento do inversor CFW08 (WEG), no controle de velocidade do motor de indução.

PALAVRAS-CHAVE: Inversor de freqüência. Eficiência Energética. Motores de Indução. Controle de Velocidade.

ABSTRACT: This work has as objective the study of energy efficiency of induction motors fed by frequency inverters, since this is a practical resource that has progressively allowed the replacement of mechanical speed reducers. In this work the speed control of induction motorsof the squirrel cage has steeped through the frequency inverters using scalar control. Induction motors are frequently used in industrial applications due to its simple construction, its low maintenance and reduced in size. It was possible through tests made at UNI-BH Electrical Engineering laboratory to obtain satisfactory results regarding the performance of the inverter CFW08 (WEG), speed control of induction motor.

KEYWORDS: Frequency inverter. Energy Efficiency. Induction Motors. Speed Control.

\section{INTRODUÇÃO}

O mercado consumidor está cada vez mais competitivo e tem exigido das indústrias produtos de melhor qualidade e custo reduzido. Para atender a essa necessidade as indústrias procuram, entre outras possibilidades, a diminuição dos seus custos variáveis, a energia elétrica consumida dentro de um processo produtivo, onde um aumento de produção pode estar diretamente ligado a um maior consumo de energia, um melhor aproveitamento deste insumo seria uma das estratégias para a diminuição dos seus custos variáveis.

Com o avanço da eletrônica de potência o controle de velocidade dos motores elétricos tem se tornando mais acessível, com isto, sistemas que antes usavam motores CC, pela facilidade de controle, hoje podem usar motores CA de indução, graças aos Inversores de Frequência, também chamados de Conversores de Frequência.

e-xacta, Belo Horizonte, v. 4, n. 1, p. 91-102. (2011) Editora UniBH Disponível em: www.unibh.br/revistas/exacta/ 
O que caracteriza o motor de indução é que só o estator fica ligado à rede de alimentação, enquanto o rotor não é alimentado externamente e as correntes, que circulam nele, são induzidas eletromagneticamente pelo estator. Assim, o funcionamento do motor de indução pode ser comparado a de um transformador onde 0 enrolamento primário deste transformador é o estator e o enrolamento secundário é o rotor. Estes geram um campo magnético, criado pelas correntes do rotor gerando, por sua vez, um novo campo magnético distribuído, atraído pelo campo do estator, à semelhança do que ocorre com os polos de dois imãs. A força de atração se traduz num torque que atua sobre o eixo do rotor, fazendo-o girar.

\section{ENSAIOS A VAZIO E COM ROTOR BLOQUEADO}

Os ensaios de motor a vazio e de rotor bloqueado tem como objetivo o estudo das propriedades e características dos motores de indução na prática, observando como são realizadas as conexões do circuito com os motores e as conexões mecânicas com os equipamentos auxiliares. Através destes ensaios são obtidos os parâmetros dos motores, os quais são necessários para determinar a representação do circuito equivalente, possibilitando efetuar os cálculos que determinam o desempenho dos mesmos (DEL TORO, 1999).

O ensaio a vazio é executado na frequência nominal, este fornece informações relativas à corrente de excitação e as perdas a vazio, nesta situação a corrente de rotor é a mínima necessária para produzir conjugado suficiente para superar as perdas por atrito e ventilação, que são associadas a rotação. As perdas a vazio $\left(\mathrm{I}^{2}-\mathrm{R}\right)$ do rotor são, portanto muito baixas e podem ser desprezadas, já no estator do motor, as perdas a vazio $\left(I^{2} * R\right)$ podem ser apreciáveis devido a essa corrente de excitação ser mais elevada, aproximadamente, $30 \%$ da corrente nominal.
O ensaio de rotor bloqueado é executado de modo que o rotor não possa girar, sendo desta forma o escorregamento igual à unidade. A impedância de rotor bloqueado pode ser afetada pela posição do rotor, no entanto, em rotores de gaiola de esquilo este efeito é pequeno. Outra alteração que se deve levar em consideração é que a impedância de dispersão pode ser afetada pela saturação magnética dos caminhos de fluxo de dispersão e pela frequência do rotor.

\section{Metodologia}

Através dos parâmetros reais de um motor gaiola de esquilo industrial foram efetuados os cálculos teóricos por meio de equações apresentadas por Fitzgerald, Kingsley JR e Kusko (2006). que determinam as características e desempenho do motor. Após serem realizados os cálculos foram inseridos os mesmos parâmetros em um aplicativo desenvolvido em DELPH por Souza (2008), para verificar a veracidade dos valores calculados, possibilitando também a visualização dos gráficos de (torque, corrente e potência), versus escorregamento.

Para demonstrar como são realizados os ensaios de motor a vazio e rotor bloqueado, em qualquer motor de indução foram utilizados um motor de rotor bobinado didático, disponível no laboratório de máquinas de elétricas do UniBH.

Com o intuito de demonstrar como a velocidade dos motores de indução, tipo gaiola de esquilo, é controlada através do inversor de freqüência, no modo escalar foi parametrizado o inversor de frequência para controlar o motor, ambos também disponíveis no laboratório do UNI-BH.

\section{Resultados}

Com os dados reais de um motor gaiola de esquilo, abaixo descrito, e com a inserção destes dados no 
aplicativo, já mencionado neste trabalho, foi possível encontrar os seguintes resultados:

Um motor de indução trifásico, ligado em estrela, de seis polos, $220 \vee$ (tensão de linha), 10 VC $(7360 \mathrm{w})$, $60 \mathrm{~Hz}$ em tensão e freqüência nominal escorregamento de $2 \%$ com perdas a vazio de $413 \mathrm{w}$ independente da carga, tem os seguintes parâmetros, referidos ao estator:

$\mathrm{R} 1=0,294 \Omega /$ fase

$\mathrm{R} 2=0,144 \Omega /$ fase

$\mathrm{X} 1=0,503 \Omega /$ fase

$X 2=0,209 \Omega /$ fase

$\mathrm{Xm}=13,25 \Omega /$ fase

\subsection{MÉTOdos do CIRCUITO EQUIVALENTE}

O circuito equivalente é usado para determinar uma ampla variedade de características de desempenho das máquinas de indução, cujos dados inseridos no aplicativo, desenvolvido em DELPH, geraram o circuito representado na Figura 1.

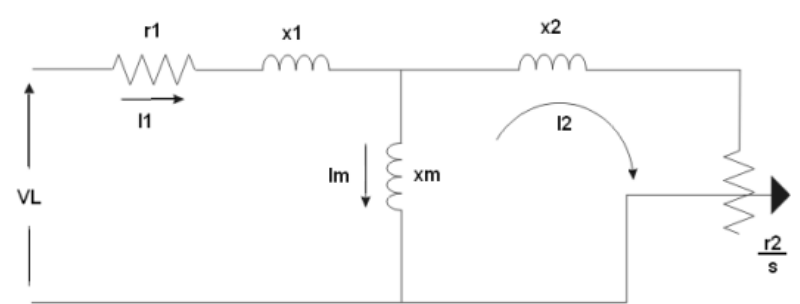

FIgURA 1 - Circuito Equivalente de um Motor de Indução, com a Resistência de Perdas no Núcleo Desprezadas

Todas as equações descritas abaixo foram retiradas de (FITZGERALD; KINGSLEY JR; KUSKO, 2006).

Com as equações relacionadas a seguir foi possível a simplificação do circuito equivalente do motor de indução através do teorema de Thévenin, convertido no circuito representado pela Figura 2 .
Impedância equivalente de Thévenin.

$\mathrm{Zth}=\frac{(\mathrm{r} 1+j \mathrm{x} 1) \times \mathrm{j} \mathrm{xm}}{\mathrm{r} 1+j(\mathrm{x} 1+\mathrm{mm})}(\Omega)$

onde: $\mathrm{Z}$ th = impedância Thévenin [V]

$$
\begin{aligned}
& r 1 \text { = resistência do estator }[\Omega] \\
& \text { jw1 }=\text { reatância de dispersão do estator }[\Omega] \\
& \text { jxm }=\text { reatância de magnetização }[\Omega] .
\end{aligned}
$$

Tensão equivalente de Thévenin.

$$
\mathrm{Vth}=\frac{\mathrm{V} 1 \mathrm{sj} \mathrm{xm}}{[\mathrm{r} 1+\mathrm{j}(\mathrm{x} 1+\mathrm{xm})]}(v)
$$

onde: $\mathrm{V}$ th = tensão Thévenin $[\mathrm{V}]$

$$
\begin{aligned}
\mathrm{V} 1 & =\text { tensão no estator }[\mathrm{V}] \\
r 1 & =\text { resistência do estator }[\Omega] \\
\mathrm{j} \mathrm{x} 1 & =\text { reatância de dispersão do estator }[\Omega] \\
\mathrm{j} \mathrm{xm} & =\text { reatância de magnetização }[\Omega] .
\end{aligned}
$$

Corrente 12.

$$
\begin{gathered}
\mathrm{I2}=\frac{\mathrm{Vth}}{\mathrm{Zth}+\mathrm{x} z+\frac{\mathrm{Nz}}{3}}(\mathrm{~A}) \\
\text { onde: } \mathrm{I} 2=\text { corrente no rotor }[\mathrm{A}] \\
\mathrm{Vth}=\text { tensão Thévenin }[\mathrm{V}] \\
\mathrm{Zth}=\text { impedância Thévenin }[\mathrm{V}] \\
\mathrm{r} 2=\text { resistência do rotor }[\Omega] \\
\mathrm{x} 2=\text { reatância do rotor }[\Omega] \\
\mathrm{s}=\text { escorregamento }[\%] .
\end{gathered}
$$

Corrente magnetização.

$$
\operatorname{Im}=\frac{\mathrm{vth}}{\mathrm{j} \mathrm{xm}}(\mathrm{A})
$$


onde: $\operatorname{Im}=$ corrente de magnetização $[\mathrm{A}]$

Vth $=$ tensão Thévenin [V]

jxm = reatância de magnetização $[\Omega]$.

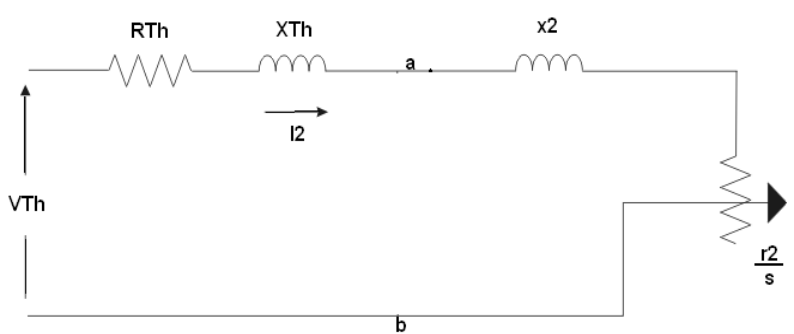

FIgURA 2 - Circuito Equivalente de um Motor de Indução, a partir dos Cálculos de Thévenin.

As equações para determinação das características de desempenho dos motores de indução foram baseadas nos dados de tensão e corrente no estator, em ligação estrela.

$\mathrm{Vf}=\frac{\mathrm{vl}}{\sqrt{2}}(v)$

onde: $\mathrm{V} 1=$ tensão de fase $[\mathrm{V}]$

$\mathrm{V}]=$ tensão de linha [V].

$$
\text { If }=\prod(A)
$$

onde: II $=$ corrente de fase $[\mathrm{A}]$

$$
\text { Il = corrente de linha }[A] \text {. }
$$

Ligação em delta.

If $=\frac{11}{\sqrt{2}}(\mathrm{~A})$

onde: If $=$ corrente de fase $[\mathrm{A}]$

$\mathrm{Il}=$ corrente de linha $[\mathrm{A}]$.

$\mathrm{Vf}=\mathrm{V} 1(\mathrm{v})$

onde: $\mathrm{V} 1=$ tensão de fase $[\mathrm{V}]$

$$
\text { Il = tensão de linha [V]. }
$$

Velocidade síncrona.

$\mathrm{ns}=\frac{120 \times \mathrm{f}}{\mathrm{p}}(\mathrm{rpm})$

onde: $\mathrm{ns}=$ velocidade síncrona em [rpm]

$$
\mathrm{f}=\text { frequência nominal }[\mathrm{Hz}]
$$

$\mathrm{p}=$ número de polos.

Velocidade retórica.

$\mathrm{nr}=\mathrm{ns} *(1-\mathrm{s})(\mathrm{rpm})$

onde: $\mathrm{ns}=$ velocidade síncrona em [rpm]

$$
\begin{aligned}
\mathrm{nr} & =\text { velocidade retórica [rpm] } \\
\mathrm{s} & =\text { escorregamento [\%]. }
\end{aligned}
$$

Rendimento.

$$
n=\frac{\text { Psaida }}{\text { Pentrada }}(\%)
$$

onde: $\mathbf{n}=$ rendimento [\%]

Psaida = potência de saída [w]

$$
\text { Pe }=\text { potência de entrada }[\mathrm{w}]
$$

Conjugado.

\section{Tpartida $=$}

$\frac{1}{\mathrm{ws}} * \frac{\mathrm{q} \times \mathrm{r} 2 \mathrm{v} \mathrm{Vh}^{2}}{\left[(\mathrm{Rth}+\mathrm{r} 2)^{2}+(\mathrm{xth}+\mathrm{x} 2)^{2}\right]}(\mathrm{Nm})$

onde: Rth = resistência Thévenin $[\Omega]$

$$
\begin{aligned}
& \mathrm{xth}=\text { reatância de Thévenin }[\Omega] \\
& \mathrm{x} 2=\text { reatância do rotor }[\Omega] \\
& \mathrm{ws}=\text { frequência angular }(\mathrm{w}) \text {. }
\end{aligned}
$$


Frequência angular.

Ws $=\frac{4 \mathrm{~s}_{\mathrm{gf}}}{\mathrm{p}}(\mathrm{rpm})$

onde: $f=$ frequência nominal $[\mathrm{Hz}]$

$$
\begin{aligned}
& \text { ws = frequência angular }[\mathrm{w}] \\
& \mathrm{p}=\text { número de pólos. }
\end{aligned}
$$

Potência de saída.

Ps $=$ Pu - Pavazio $(w)$

onde: $\mathrm{PS}=$ potência de saída [w]

$$
\text { Fu = potência útil }[w]
$$

Pavazio = potência de ensaio a vazio $[\mathrm{w}]$.

Potência de entrada.

$\mathrm{Pe}=\mathrm{q} * \mathrm{Vl} * \mathrm{Ll} * \cos \theta(\mathrm{w})$

onde: $\mathrm{V}]=$ tensão de linha [V]

$$
\begin{aligned}
& \text { Il }=\text { corrente de linha }[A] \\
& \mathrm{Pe}=\text { potência de entrada }[\mathrm{w}] \\
& \mathrm{q}=\text { número de fases. }
\end{aligned}
$$

Potência dissipada no enrolamento do estator.

$$
\mathrm{Pab}=\mathrm{q} * \mathrm{r} 1 * 12^{2}(\mathrm{w})
$$

onde: $\mathrm{Pab}=$ potência total transferida através do entreferro $[w]$

$$
q=\text { número de fases } \mathrm{r} 1 \text { = resistência do estator }[\Omega] \text {. }
$$

Potência total transferida através do entreferro.

$\mathrm{Pab}=\mathrm{q} * \frac{\mathrm{r} 2}{\mathrm{~s}} * 12^{2}(\mathrm{w})$

onde: $\mathrm{Pab}=$ potência total transferida através do entreferro $[\mathrm{w}]$ $\mathrm{q}=$ número de fases $\mathrm{r} 2=$ resistência do rotor $[\Omega]$ corrente $[\Omega]$

I2 = corrente de magnetização $[\mathrm{A}]$

$\mathrm{s}=$ escorregamento.

Potência dissipada no enrolamento.

$\operatorname{Pcr}=\mathrm{q} * \mathrm{r} 2 * \mathbb{I}^{2}(w)$

onde: $\mathrm{Pcr}=$ Potência dissipada no enrolamento [w]

$q$ = número de fases

r2 = resistência do rotor $[\Omega]$

12 = corrente de magnetização [A].

Potência útil.

$\mathrm{Pu}=\mathrm{Pab}-\mathrm{Pcr}(\mathrm{w})$

onde: $\mathrm{Pu}=$ potência útil [w]

Pab = potência total transferida através do entreferro [w]

$\mathrm{PCr}=$ potência dissipada no enrolamento [w].

Com a inserção de dados de um motor real no software programados em DELPH, calculou-se as características do motor de indução para o qual, os resultados apresentados pelas figuras 3 e 4 foram obtidos.

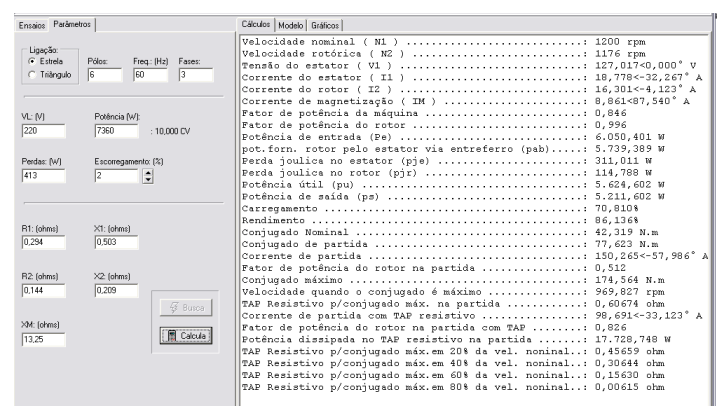

FIGURA 3 - Cálculos de Escorregamento em 2\%.

e-xacta, Belo Horizonte, v. 4, n. 1, p. 91-102. (2011) Editora UniBH Disponível em: www.unibh.br/revistas/exacta/ 


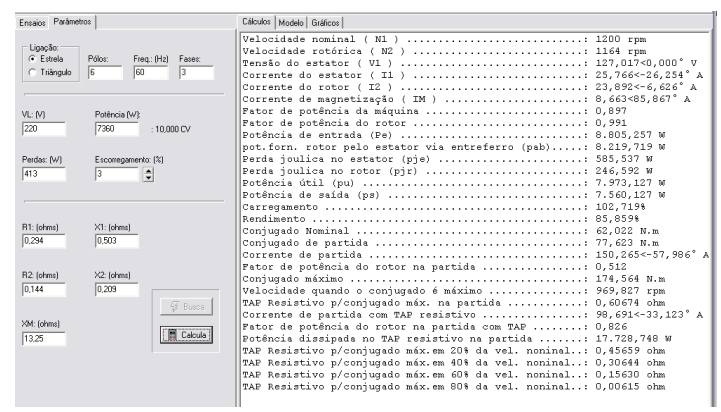

FIGURA 4 - Cálculos de Escorregamento em 3\%.

\subsection{ENSAIOS A VAZIO O ROTOR BLOQUEADO}

Os ensaios a vazio do motor de indução foram diagramados, conforme a Figura 5, com o intuito de demonstrar como os instrumentos foram inseridos para a realização das medições dos parâmetros do motor.

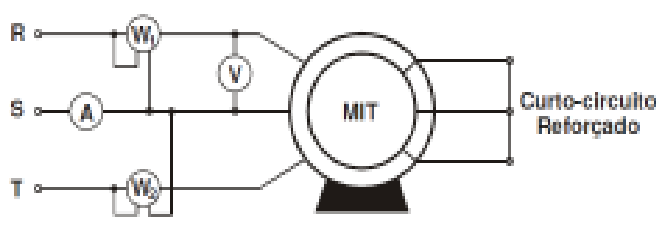

FIGURA 5 - Diagrama Esquemático dos Ensaios

\subsubsection{MÉTOdO DO ROTOR BLOQUEADO}

Este ensaio foi executado no Laboratório de Máquinas UniBH no primeiro semestre de 2011, para determinar a impedância equivalente referida à armadura por fase (Zeraf), a resistência equivalente referida à armadura por fase (Reraf) e a reatância equivalente referida à armadura por fase (Xeraf) do motor de indução trifásico.

Este ensaio pode ser realizado em ligações em estrela ou delta, no entanto, para este ensaio foi utilizado a ligação em delta com uma tensão de entrada de 220 VCA, através de dois transformadores que foram ligados em paralelo, após travar o eixo do rotor, que neste caso foi feito manualmente (Figura 6).

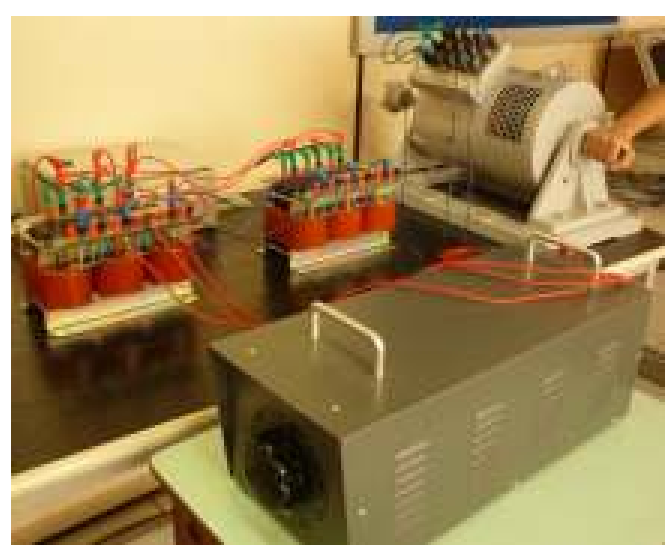

FIGURA 6 - Ensaio de Rotor Bloqueado destacando em primeiro plano o varivolt, em segundo plano à esquerda os dois transformadores e à dierita o motor bobinado

As medições realizadas pelos Wattímetros (Figura 7) foram utilizadas para obter os dados necessários aos cálculos dos parâmetros do motor de indução.

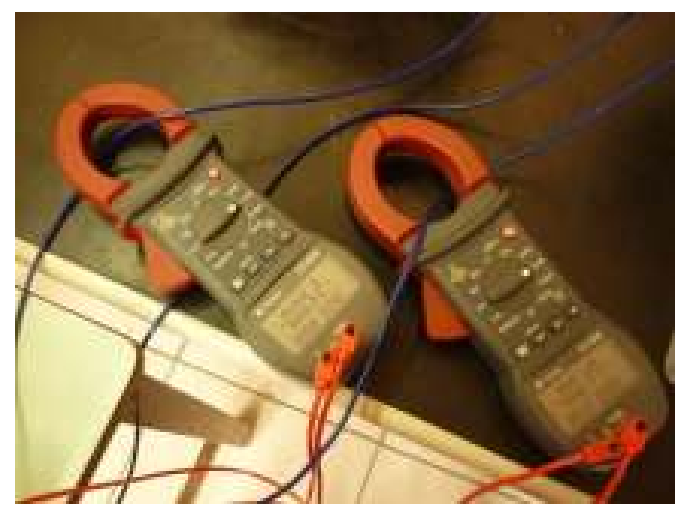

FIGURA 7 - Detalhe dos Wattímetros utilizados no ensaio de Rotor Bloqueado

Através de um varivolt foi possível variar a tensão aplicada ao motor até atingir a corrente nominal, e ao mesmo tempo curto circuitar os terminais de enrolamento do rotor.

O wattímetros indicaram a potência total com rotor bloqueado (Ptbl), isto é,

$\mathrm{Ptbl}=\mathrm{W} 1 .-\mathrm{W} 2$.

Dados do ensaio:

Alimentação de rede: 220 VCA 
As tabelas 1, 2 e 3 apresentadas a seguir contêm os dados de placas dos equipamentos utilizados para realização deste ensaio.

\section{TABELA 1}

Dados de placa do motor de indução rotor bobinado

\begin{tabular}{|l|l|}
\hline Modelo & EA4-5A (Equacional) \\
\hline Potência Nominal & $2.2 \mathrm{Kw}$ \\
\hline Fases & 3 \\
\hline Frequência & $60 \mathrm{~Hz}$ \\
\hline Rotação Nominal & $1690 \mathrm{rpm}$ \\
\hline Ligação em Estrela & $220 \mathrm{~V} / 9 \mathrm{~A}$ \\
\hline Ligação em Delta & $380 \mathrm{~V} / 5,2 \mathrm{~A}$ \\
\hline
\end{tabular}

TABELA 2

Dados de placa dos transformadores

\begin{tabular}{|l|l|}
\hline Modelo & King \\
\hline Potência Nominal & $7 \mathrm{KVA}$ \\
\hline Frequência & $60 \mathrm{~Hz}$ \\
\hline Tensão & $220 \mathrm{~V}-440 \mathrm{~V}$ \\
\hline Corrente & $2,6 \mathrm{~A}-1,3 \mathrm{~A}$ \\
\hline
\end{tabular}

TABELA 3

Dados de placa do auto-transformador variável

(Varivolt)

\begin{tabular}{|l|l|}
\hline Modelo & T 3410 (Auto Trafo) \\
\hline Potência Nominal & $4,2 \mathrm{Kw}$ \\
\hline Fases / Frequência & $3 / 60 \mathrm{~Hz}$ \\
\hline Tensão Entrada & $220 \mathrm{VCA}$ \\
\hline Tensão de Saída & $0-240 \mathrm{VCA}$ \\
\hline Corrente & $10 \mathrm{~A}$ \\
\hline
\end{tabular}

\subsubsection{MÉtodo de enSAIO A VAZIO}

O ensaio a vazio (Figura 8) foi executado no Laboratório de Máquinas do UNI-BH, no primeiro semestre de 2011, para determinar a potência rotacional ( Prot ) do motor de indução trifásico.

Este ensaio pode ser realizado em ligações em estrela ou delta, no entanto este foi ligado em estrela com uma tensão de entrada de 380 VCA através de dois transformadores os quais foram ligados em paralelo.

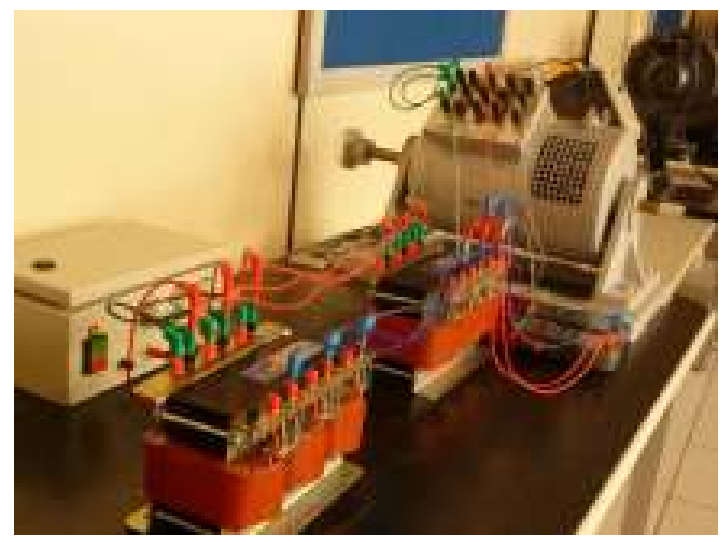

FIgURA 8 - Ensaio de Motor a Vazio, destacando em primeiro plano os transformadores e em segundo plano o motor bobinado

O motor é posto a girar a vazio de maneira que a potência total ( $\mathrm{Pt}$ ) é constituída pela potência na resistência equivalente referida a armadura ( Prera ) e pela potência rotacional : $\mathrm{Pt}=$ Prera + Prot, Onde, $\mathrm{Pt}$ é a leitura dos wattímetros no ensaio a vazio, $\mathrm{Pt}=\mathrm{W} 1+\mathrm{W} 2$; Reraf é a resistência equivalente referida a armadura, por fase, obtida no ensaio de curto-circuito; e laf é a corrente de armadura por fase no ensaio a vazio.

Dado do ensaio:

Alimentação de rede: 220 VCA

As tabelas 4 e 5 apresentadas a seguir contêm os dados de placas dos equipamentos utilizados para realização deste ensaio 
TABELA 4

Dados de placa do motor de indução rotor bobinado

\begin{tabular}{|l|l|}
\hline Modelo & EA4-5A (Equacional) \\
\hline Potência Nominal & $2.2 \mathrm{Kw}$ \\
\hline Fases & 3 \\
\hline Frequência & $60 \mathrm{~Hz}$ \\
\hline Rotação Nominal & $1690 \mathrm{rpm}$ \\
\hline Ligação em Estrela & $220 \mathrm{~V} / 9 \mathrm{~A}$ \\
\hline Ligação em Delta & $380 \mathrm{~V} / 5,2 \mathrm{~A}$ \\
\hline
\end{tabular}

TABELA 5

Dados de placa dos transformadores

\begin{tabular}{|l|l|}
\hline Modelo & King \\
\hline Potência Nominal & $7 \mathrm{KVA}$ \\
\hline Frequência & $60 \mathrm{~Hz}$ \\
\hline Tensão & $220 \mathrm{~V}-440 \mathrm{~V}$ \\
\hline
\end{tabular}

As medições realizadas pelos Wattímetros e Tacômetro (Figura 9) foram utilizadas para obter os dados necessários aos cálculos dos parâmetros do motor de indução.

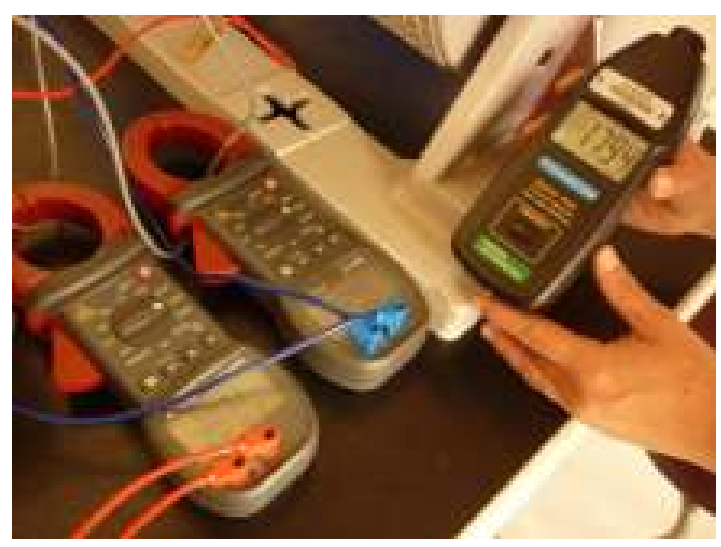

FIGURA 9 - Wattímetro e tacômetro utilizados nos Ensaio de Motor a Vazio para obtenção das medidas.

\subsection{MÉTODO DA PARAMETRIZAÇÃO DO INVERSOR}

O objetivo da parametrização dos inversores de frequência é controlar a velocidade no motor do tipo gaiola de esquilo, inserindo os parâmetros corretos, em função das operações: do tipo e dos dados do motor (WEG, 2005)

Os dados necessários para realizar a parametrização do Inversor foram obtidos pela coleta de dados de placa do motor e do inversor de freqüência apresentadas pelas tabelas 6 e 7 ..

\section{TABELA 6}

Dados de placa do motor de indução gaiola de esquilo

\begin{tabular}{|l|l|}
\hline Modelo & CE (WEG) \\
\hline Potência Nominal & $0,25 \mathrm{Kw}(0,33 \mathrm{CV})$ \\
\hline Rotação Nominal & $1710 \mathrm{rpm}$ \\
\hline Ligação em Estrela & $220 \mathrm{~V} / 1,44 \mathrm{~A}$ \\
\hline Ligação em Delta & $380 \mathrm{~V} / 0,834 \mathrm{~A}$ \\
\hline
\end{tabular}

TABELA 7

Dados do Inversor de Frequências

\begin{tabular}{|l|l|}
\hline Modelo & CFW08 (WEG) \\
\hline Versão de Software & 3.98, revisão 46 \\
\hline Tensão de Entrada & 200 - 240V AC \\
\hline Corrente de Entrada & $3,1 \mathrm{~A} / 60 \mathrm{~Hz}$ \\
\hline Corrente de Saída & $2,6 \mathrm{~A}$ \\
\hline Frequência de Saída & $0-300 \mathrm{~Hz}$ \\
\hline
\end{tabular}

Os procedimentos realizados pela parametrização básica do inversor no módulo escalar foram desenvolvidos em 19 passos, realizados no Laboratório de Máquinas do UNI-BH, no primeiro semestre de 2011, através dos comandos via IHM 
(Interface Homem Máquina) utilizando a estratégia de controle escalar.

1 - Configurar os enrolamentos de estator do motor de indução para ligação em triângulo (para alimentação em 220 v).

2 - Conectar a alimentação do motor à saída do inversor

3 - Conectar a entrada do inversor à rede elétrica trifásica de 220v, $60 \mathrm{~Hz}$. o inversor será energizado aparecendo a palavra rdy no visor da IHM (ready = pronto para uso) (Figura 10).

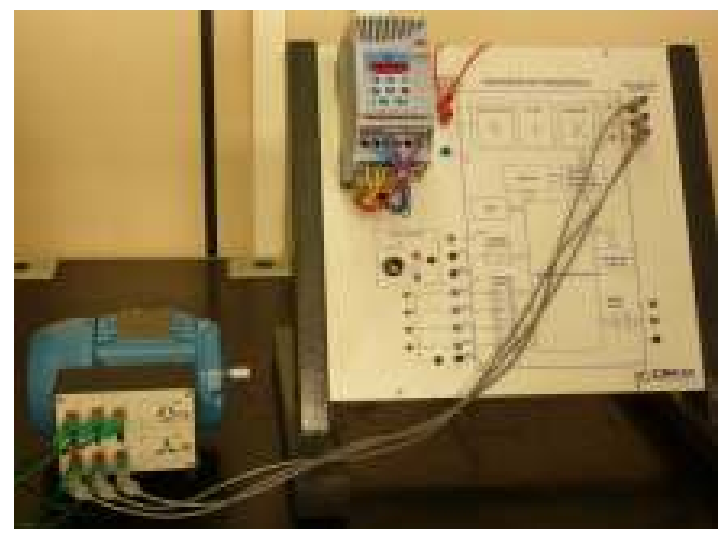

FIGURA 10 - Detalhe da ligação do motor ao painel de Inversor de Frequência para a realização do controle de velocidade

4 - Desbloquear o inversor para a alteração de valores dos parâmetros, quando o inversor é desenergizado, ele retém os últimos valores ajustados antes da desenergização, não permitindo a alteração dos mesmos. Para alterar os valores e necessário que P000 esteja configurado com o valor 5 .

5 - Definição da faixa de frequências de operação (faixa de velocidades de operação do motor) a frequência mínima é definida no parâmetro P133 e a freqüência máxima no parâmetro P134. Nesta prática o P133 foi configurado com o valor de $5 \mathrm{~Hz}$ e o P134, como o valor de $90 \mathrm{~Hz}$.
6 - O parâmetro P142 ajusta a tensão máxima de saída do inversor, este parâmetro foi ajustado em $100 \%$ do valor da tensão de rede.

7 - Através do parâmetro P145 foi ajustada a freqüência de inicio do enfraquecimento de campo, com o valor da freqüência de $60 \mathrm{~Hz}$ (Freqüência Nominal do Motor).

8 - O parâmetro P156 define a corrente de sobrecarga este foi ajustado para o valor de 1,73 $\mathrm{A}$, que equivale a $20 \%$ superior ao valor da corrente nominal do motor.

Define-se como corrente de sobrecarga a máxima corrente que será permitida na saída do inversor em regime contínuo de funcionamento. Correntes de saída acima deste valor provocam o desligamento do inversor. O tempo de desligamento é regido por uma curva corrente versus tempo semelhante àquelas de dispositivos de proteção como, por exemplo, relés de sobrecarga. Quanto mais severa for a sobrecarga, mais rapidamente o inversor será desligado; este parâmetro não atua em sobrecargas transitórias de curta duração, como é o caso das partidas dos motores.

9 - Através do parâmetro P169 foi definido a máxima corrente de saída do inversor, ajustada com o valor de duas vezes a corrente nominal do motor que equivale a 2,88 A. A máxima corrente de saída serve como um limitador no valor da corrente de saída do inversor. Este parâmetro não atua no sentido de desligar o inversor, ele promove a saturação da corrente de saída no valor ajustado.

10 - Definição da referência de velocidade, neste passo são definidos três parâmetros tempo de aceleração, o tempo desaceleração e a frequência correspondente à velocidade de operação. Pelo parâmetro P100 foi definido o tempo de aceleração com o valor de $6 \mathrm{~s}$, com o parâmetro P101, estabeleceu-se o tempo de desaceleração com o valor de $12 \mathrm{~s}$ e, com o P121, a frequência correspondente à 
velocidade de operação foi registrado o valor de $45 \mathrm{~Hz}$.

11 - Foi configurado o parâmetro P220 com o valor de zero para determinar a operação local.

12 - O parâmetro P221 foi configurado com o valor de zero, o que indica que a referência de velocidade foi fornecida a através das teclas da IHM.

13 - Foi definida a origem dos comandos através do parâmetro P229 com o valor de zero, indicando que a origem dos comandos será as teclas da IHM.

14 - O parâmetro P231 foi configurado com o valor 2 para definição da seleção do sentido de giro por comando.

15 - Através do parâmetro P202, configurado com o valor zero, foi selecionada a operação com a estratégia de controle escalar.

16 - Com o parâmetro P005 foram possíveis visualizar a freqüência de saída do inversor (Figura 11).

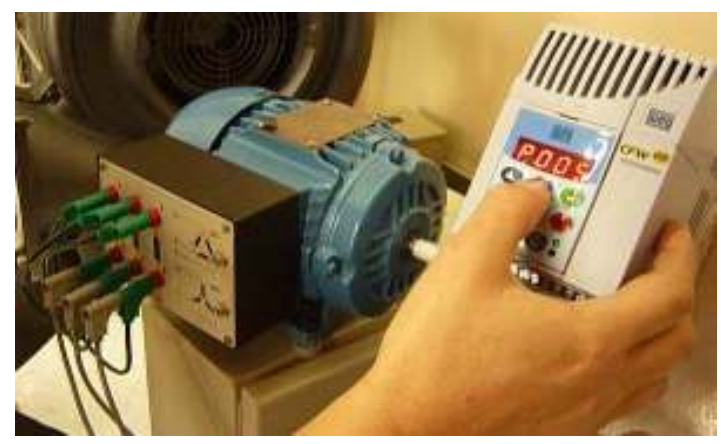

FIGURA 11 - Parametrização do Inversor de Frequência Valores

18 - A leitura da tensão de saída do inverso é visualizada através do parâmetro P003.

19 - A leitura da corrente de saída do inverso é visualizada através do parâmetro P007.

Na Tabela 7 são apresentados os valores visualizados através da IHM do inversor de frequência CFW08 (WEG).

\section{TABELA 7}

Valores Visualizados pelo IHM do Inversor de Frequência

\begin{tabular}{|c|c|c|c|}
\hline Freq. $(\mathrm{Hz})$ & Conj. (Nm) & $\begin{array}{l}\text { Corr. } \\
\text { (A) }\end{array}$ & $\begin{array}{c}\text { Ten. } \\
\text { (V) }\end{array}$ \\
\hline 5 & 5,7 & 1,26 & 28,5 \\
\hline 8 & 4,88 & 1,29 & 39,1 \\
\hline 11 & 4,49 & 1,35 & 49,4 \\
\hline 14 & 4,3 & 1,37 & 60,2 \\
\hline 17 & 4,19 & 1,36 & 71,2 \\
\hline 20 & 4,08 & 1,35 & 81,6 \\
\hline 23 & 3,98 & 1,34 & 91,6 \\
\hline 26 & 3,96 & 1,33 & 103 \\
\hline 29 & 3,89 & 1,32 & 113 \\
\hline 32 & 3,84 & 1,32 & 123 \\
\hline 35 & 3,83 & 1,31 & 134 \\
\hline 38 & 3,82 & 1,3 & 145 \\
\hline 41 & 3,78 & 1,3 & 155 \\
\hline 44 & 3,78 & 1,28 & 167 \\
\hline 47 & 3,72 & 1,27 & 175 \\
\hline 50 & 3,72 & 1,26 & 186 \\
\hline 53 & 3,71 & 1,25 & 197 \\
\hline 56 & 3,71 & 1,24 & 208 \\
\hline 59 & 3,7 & 1,23 & 218 \\
\hline 60 & 3,7 & 1,23 & 220 \\
\hline 62 & 3,54 & 1,16 & 220 \\
\hline 65 & 3,39 & 1,06 & 220 \\
\hline 68 & 3,24 & 0,97 & 220 \\
\hline 71 & 3,1 & 0,9 & 220 \\
\hline 74 & 2,97 & 0,84 & 220 \\
\hline 77 & 2,86 & 0,79 & 220 \\
\hline 80 & 2,77 & 0,75 & 220 \\
\hline 83 & 2,65 & 0,71 & 220 \\
\hline 86 & 2,55 & 0,68 & 220 \\
\hline 90 & 2,44 & 0,65 & 220 \\
\hline
\end{tabular}

Foram plotados os gráficos (Conjugado e Tensão) versus Frequência, representados nas figuras 22 e 23 através dos valores visualizados pelo IHM do inversor de frequência CFW08 (WEG).

Entre as freqüências 25 a $60 \mathrm{~Hz}$ foi obtido um conjugado com valores que podem ser considerados 
constante e, acima da freqüência nominal $(60 \mathrm{~Hz})$, foi verificado que houve o enfraquecimento de campo, pois a tensão permaneceu constante com o seu valor nominal e a freqüência aumenta, devido a isto, a corrente de magnetização da máquina cai e com ela o fluxo magnético estabelecido no entreferro. Consequentemente $\mathrm{O}$ conjugado disponibilizado também sofre uma queda (Figura 12).

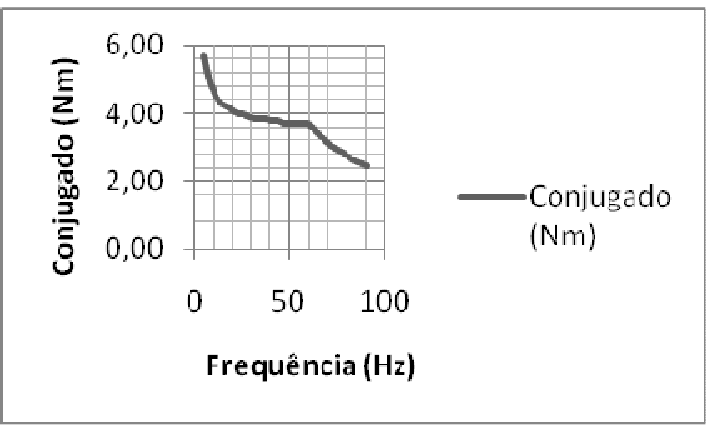

FIGURA 12 - Conjugado x Frequência

Como o controle escalar baseia-se na relação V/F, visando mantê-la constante, ou seja, quando o motor trabalha com o fluxo aproximadamente constante pode ser observado no gráfico da Figura 13, que a tensão aumenta em uma mesma relação com a freqüência, até a tensão nominal do motor (220 V), pois caso a tensão continue crescendo com o aumento da freqüência, pode-se causar danos ao enrolamento do motor.

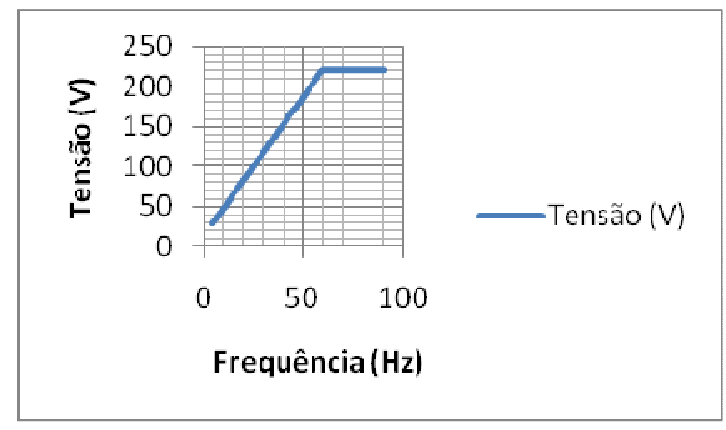

FIGURA 13 - Tensão x Frequências

\section{CONCLUSÃo}

A utilização de inversor de frequência do motor de indução gaiola de esquilo têm crescido rapidamente, pois estes equipamentos estão se tornando cada vez mais práticos e econômicos.

Por este motivo foi abordado neste trabalho o controle da velocidade do motor de indução com a utilização do inversor de freqüência, trabalhando no modo escalar, o qual pode ser uma solução eficiente e econômica nos processo industriais eliminando os picos de partida e as rotações desnecessárias.

O motor de indução é diretamente controlado pelo inversor de freqüência, onde o usuário define através de parâmetros as seguintes variáveis: velocidade, tensão, corrente, aceleração, desaceleração.

O uso do inversor de frequência para estes fins se torna prático devido sua fácil parametrização e instalação, além das muitas opções na hora da compra, pois possui vários modelos e fabricantes.

Através dos parâmetros reais obtidos para um motor gaiola de esquilo industrial foram efetuados os cálculos teóricos por meio de equações que determinam as características e o desempenho do motor, após serem realizados os cálculos, foi inserido os mesmos parâmetros em um aplicativo desenvolvido em DELPH para verificar a veracidade dos valores calculados.

Apesar do laboratório de máquina do Curso de Engenharia Elétrica do UniBH possuir uma excelente infraestrutura não foi possível realizar os ensaios a vazio e de rotor bloqueado no motor gaiola de esquilo como era o objetivo deste trabalho, pois o motor deste tipo disponível no laboratório tem uma corrente nominal baixa $(<1 \mathrm{~A})$ e os equipamentos utilizados para medir esta grandeza são incompatíveis, uma vez que foram adquiridas para medir correntes nominais acima de $1 \mathrm{~A}$

No entanto, o ensaio foi realizado em um motor de rotor bobinado com o intuito de demonstrar como estes ensaios são realizados, tanto para motor do tipo gaiola de esquilo quanto para o de rotor bobinado. 
Foram alcançados resultados satisfatório em relação ao desempenho do funcionamento do inversor CFW08 (WEG) em relação ao controle de velocidade no modo escalar do motor de indução gaiola de esquilo WEG de $250 \mathrm{~W}$ de potência, sendo possível a análise da faixa de frequência em que o torque permanece constante e a região de enfraquecimento de campo do mesmo, que se encontra acima da frequência nominal $(60 \mathrm{~Hz})$.

Foi observado que os inversores possibilitam que os motores sejam acionados suavemente, sem trancos.
Com isso, reduz-se a quebra de elementos de transmissão como correntes e rodas dentadas, ocorrências frequentes, em virtude do esforço adicional provocado pelos motores com partida direta.

\section{AgRADECIMENTOS}

Os autores agradecem ao UniBH por ter disponibilizado o Laboratório de Máquinas Elétricas para a realização e conclusão deste trabalho.

\section{REFERÊNCIAS}

AMARAL, M. V.; Motor. Aplicativo desenvolvido em DELPH, 2008..

DEL TORO, Vincent. Fundamentos de Máquinas Elétricas. Única ed. Rio de Janeiro: Editora LTC, 1999.
FITZGERALD, A. E.; KINGSLEY JR, C.; KUSKO, A. Máquinas Elétricas. $6^{\circ}$ Ed. Porto Alegre: Editora Bookman, 2006.

WEG. Motores de indução alimentados por conversores de freqüência PWM. Jaraguá do Sul SC. 2005. Disponível em <http://www.weg.com.br>. Acesso em: 25 set. 2010. 